International Journal of Pure and Applied Mathematics

Volume 105 No. 1 2015, 39-57

ISSN: 1311-8080 (printed version); ISSN: 1314-3395 (on-line version)

url: http://www.ijpam.eu

doi: http://dx.doi.org/10.12732/ijpam.v105i1.5

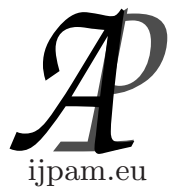

\title{
VAGUE POSITIVE IMPLICATIVE AND VAGUE ASSOCIATIVE LI - IDEALS OF LATTICE IMPLICATION ALGEBRAS
}

\author{
T. Anitha ${ }^{1 \S}$, Babu V. Amarendra ${ }^{2}$ \\ ${ }^{1}$ Department of Mathematics \\ K.L. University \\ Vaddeswaram, Guntur, 522 502, INDIA \\ ${ }^{2}$ Department of Mathematics \\ Achraya Nagarjuna University \\ Nagarjuna Nagar, 522510, INDIA
}

\begin{abstract}
We vaguefy the concepts of positive implicative LI - ideals and associative LI - ideals of lattice implication algebras. We investigate the connections to related classes. Also we provide the equivalent conditions for both vague positive implicative LI - ideals and vague associative LI - ideals. Extension property of a vague positive implicative LI - ideal is built. Also We studied some equivalent conditions for vague implicative LI - ideals. And finally, we prove that in a lattice implication algebra, the concepts of vague implicative and vague positive implicative LI - ideals coincide.
\end{abstract}

AMS Subject Classification: 03G10, 08A72, 03E72

Key Words: lattice implication algebras, VLI - ideals, VILI - ideals, VPILI - ideals and vague associative LI - ideals

\section{Introduction}

In order to research the logical system whose proportional value is given in a lattice, Y. XU [14] proposed the concept of lattice implication algebras, and

Received: July 17, 2015

(C) 2015 Academic Publications, Ltd.

$\S$ Correspondence author url: www.acadpubl.eu 
discussed their some properties. Y.XU, Y.B. Jun and E.H. Roh [12] introduced the notion of LI - ideals of a lattice implication algebras. Y.Lin Liu, San Yang Liu, Y.Xu, Ke Yun Qin [15] introduced the notion of ILI - ideals of lattice implication algebras. Later on, other researchers studied several LI -ideals of lattice implication algebras. In particular, A. Ahmadi, S. Mokhtari, A. Kordi, Moussavi [5] introduced the concept of positive implicative LI - ideals and associative LI - ideals of lattice implication algebras and discussed their some properties.

The concept of fuzzy set was intrduced by Zadesh [1]. With the development of fuzzy set, it is widely used in many fields. Meanwhile, the deficiency of fuzzy sets are also attract attention. Such as fuzzy set is single function, it cannot express the evidence of supporting and opposing. Based on this reason, the concept of vague set introduced by Gau.W.L and Buehrer.D.J[8] in 1993. Vague sets as a extension of fuzzy sets, the idea of vague sets is that the membership of every element can be divided into two aspects including supporting and opposing. Since then this idea has been applied to algebraic structures such as groups, rings and algebras like as BM - algebras, MV - algebras and BL algebras etc. Ya Qin and Yi Liu [10] applied the concept of vague set theory to lattice implication algebra and introduced the notion of v- filter, and investigated their some properties.In $[6,7]$, we introduced the notions of vague LI - idelas, vague implicative LI - ideals of lattice implication algebras and investigated some properties.

In this paper, as an extension of ours memtioned work, we introduce the notions of vague positive implicative LI - ideals and vague associative LI ideals of a lattice implication algebras and discuss some of their properties.Also we prove that in a lattice implication algebra, the concepts of vague implicative and vague positive implicative LI - ideals coincide.

Through out this article, let $L$ denote a lattice implication algebra.

\section{Preliminaries}

In this section we given some definitions and state some results for later use.

Definition 1. [14] Let $(L, \vee, \wedge, 0, I)$ be a complemented lattice with the universal bounds $0, I$. " $\rightarrow$ " is a another binary operation of $L$. In the sequel the binary operation " $\rightarrow$ " will be denoted by juxtapositin. $\left(L, \vee, \wedge, \rightarrow,{ }^{\prime}, 0, I\right)$ is called a lattice implication algebra, if the following axioms hold, $\forall x, y, z \in L$, 
$\left(I_{1}\right) x(y z)=y(x z)$

$\left(I_{2}\right) x x=I$

$\left(I_{3}\right) x y=y^{\prime} x^{\prime}$

$\left(I_{4}\right) x y=y x=I$ implies $x=y$;

$\left(I_{5}\right)(x y) y=(y x) x$;

$\left(L_{1}\right)(x \vee y) z=(x z) \wedge(y z)$

$\left(L_{2}\right)(x \wedge y) z=(x z) \vee(y z)$.

A lattice implication algebra $(L, \vee, \wedge, \rightarrow,,, 0, I)$ is called a lattice $H$ implication algebra, if it satisfy the following axiom: $x \vee y \vee((x \wedge y) z)=I, \forall x, y, z \in L$.

Definition 2. [14]Let $L$ be a lattice implication algebra, then for any $x, y, z \in L$, the following conclusions hold:

1. If $I x=I$ then $x=I$.

2. $I x=x$ and $x 0=x^{\prime}$.

3. $0 x=I$ and $x I=I$.

4. $x \leq y$ if and only if $x y=I$.

5. $x y \geq x^{\prime} \vee y$.

6. $(x z)(x y)=((z \wedge x) y)=(z x)(z y)$.

7. $(x y) \leq(z x)(z y)$.

8. $(x y) \leq(y z)(x z)$.

Definition 3. [12]Let $I$ be a nonempty subset of a lattice implication algebra $L . I$ is said to be an $L I$ - ideal of $L$ if it satisfies the following conditions:

1. $0 \in I$;

2. $\forall x, y \in L,(x y)^{\prime} \in I$ and $y \in I$ imply $x \in I$.

Definition 4. [15]Let $I$ be a nonempty subset of a lattice implication algebra $L . I$ is said to be an implicative $L I$ - ideal (briefly, ILI-ideal) of $L$ if it satisfies the following conditions:

1. $0 \in I$; 
2. $\forall x, y, z \in L,\left(\left((x y)^{\prime} y\right)^{\prime} z\right)^{\prime} \in I$ and $z \in I \operatorname{imply}(x y)^{\prime} \in I$.

Definition 5. [5]Let $I$ be a nonempty subset of a lattice implication algebra $L . I$ is said to be a positive implicative $L I$ - ideal (briefly, PILI - ideal) of $L$ if it satisfies the following conditions:

1. $0 \in I$;

2. $\forall x, y, z \in L,\left(\left(y(z y)^{\prime}\right)^{\prime} x\right)^{\prime} \in I$ and $x \in I$ imply $y \in I$.

Definition 6. [5]Let $I$ be a nonempty subset of a lattice implication algebra $L$. $I$ is said to be an associative $L I$ - ideal of $L$ if it satisfies the following conditions:

1. $0 \in I$

2. $\forall x, y, z \in L,\left((z y)^{\prime} x\right)^{\prime} \in I$ and $(y x)^{\prime} \in I$ imply $z \in I$.

Definition 7. [8]A vague set $A$ in the universal of discourse $X$ is characterized by two membership functions given by:

1. A truth membership function $t_{A}: X \rightarrow[0,1]$ and

2. A false membership function $f_{A}: X \rightarrow[0,1]$,

Where $t_{A}(x)$ is a lower bound of the grade of membership of $x$ derieved from the "evidence for $x$ ", and $f_{A}(x)$ is a lower bound on the negation of $x$ derived from the "evidence against $x$ " and $t_{A}(x)+f_{A}(x) \leq 1$. Thus the grade of membership of $x$ in the vague set $A$ is bounded by subinterval $\left[t_{A}(x), 1-f_{A}(x)\right]$ of $[0,1]$. The vague set $A$ is written as $A=\left\{\left\langle x,\left[t_{A}(x), f_{A}(x)\right]\right\rangle / x \in X\right\}$. Where the interval $\left[t_{A}(x), 1-f_{A}(x)\right]$ is called the vague value of $x$ in the vague set $A$ and denoted by $V_{A}(x)$.

Definition 8. [8] Let $A$ be a vague set of a universe $X$ with the truth membership function $t_{A}$ and the false membership function $f_{A}$. For any $\alpha, \beta \in$ $[0,1]$ with $\alpha \leq \beta$, the $(\alpha, \beta)$ - cut or vague cut of a vague set $A$ is a crisp subset $A_{(\alpha, \beta)}$ of the set $X$ given by $A_{(\alpha, \beta)}=\left\{x \in X / V_{A}(x) \geq[\alpha, \beta]\right\}$.

Definition 9. [8]The $\alpha$ - cut, $A_{\alpha}$ of the vague set $A$ is the $(\alpha, \alpha)$ - cut of $A$ and hence given by $A_{\alpha}=\left\{x \in X / t_{A}(x) \geq \alpha\right\}$ 
Notation: Let $I[0,1]$ denote the family of all closed sub intervals of $[0,1]$. If $I_{1}=\left[a_{1}, b_{1}\right], I_{2}=\left[a_{2}, b_{2}\right]$ are two elements of $I[0,1]$, we call $I_{1} \geq I_{2}$ if $a_{1} \geq a_{2}$ and $b_{1} \geq b_{2}$. We define the term imax to mean the maximum of two intervals as imax $\left[I_{1} I_{2}\right]=\left[\max \left\{a_{1}, a_{2}\right\}, \max \left\{b_{1}, b_{2}\right\}\right]$. Similarly, we can define the term imin of any two intervals.

Definition 10. [6]Let $A$ be a vague set of a lattice implication algebra $L$. $A$ is said to be a vague LI - ideal (brieflyVLI - ideal) of $L$ if it satisfies the following conditions:

1. $\forall x \in L, V_{A}(0) \geq V_{A}(x)$;

2. $\forall x, y \in L, V_{A}(x) \geq \operatorname{imin}\left\{V_{A}\left((x y)^{\prime}\right), V_{A}(y)\right\}$.

Definition 11. [7]Let $A$ be a vague set set of a lattice implication algebra $L$. $A$ is said to be a vague implicative $L I$ - ideal (brieflyVILI - ideal) of $L$ if it satisfies the following conditions:

1. $\forall x \in L, V_{A}(0) \geq V_{A}(x)$;

2. $\forall x, y, z \in L, V_{A}\left((x y)^{\prime}\right) \geq \operatorname{imin}\left\{V_{A}\left(\left(\left((x y)^{\prime} y\right)^{\prime} z\right)^{\prime}\right), V_{A}(z)\right\}$.

\section{Vague Positive Implicative LI - Ideals}

In this section, we introduce the notion of Vague positive implicative LI - ideals and investigate some of their properties.

Definition 12. Let $A$ be a vague set of $L$. $A$ is said to be a vague positive implicative LI - ideal ( briefly VPILI - ideal) of $L$ if it satisfies the following conditions:

1. $\forall x \in L, V_{A}(0) \geq V_{A}(x)$ :

2. $\forall x, y, z \in L, V_{A}(y) \geq \operatorname{imin}\left\{V_{A}\left(\left(\left(y(z y)^{\prime}\right)^{\prime} x\right)^{\prime}\right), V_{A}(x)\right\}$.

Example 13. Let $L=\{0, a, b, I\}$ be a set with cayley table as follows: 


\begin{tabular}{|c|c|c|c|c|}
\hline$\rightarrow$ & 0 & $a$ & $b$ & $I$ \\
\hline 0 & $I$ & $I$ & $I$ & $I$ \\
\hline$a$ & $b$ & $I$ & $b$ & $I$ \\
\hline$b$ & $a$ & $a$ & $I$ & $I$ \\
\hline$I$ & 0 & $a$ & $b$ & $I$ \\
\hline
\end{tabular}

Define ', $\vee, \wedge$ operations on $L$ as follows: $x^{\prime}=x \rightarrow 0, x \vee y=(x \rightarrow y) \rightarrow y$, $x \wedge y=\left(\left(x^{\prime} \rightarrow y^{\prime}\right) \rightarrow y^{\prime}\right)^{\prime}$ for all $x, y \in L$.

Then $\left(L, \vee, \wedge, \rightarrow{ }^{\prime}, 0, I\right)$ is a lattice implication algebra[14]. Let $A$ be a vague set of $L$ defined by

$$
A=\{\langle 0,[0.7,0.2]\rangle,\langle a,[0.7,0.2]\rangle,\langle b,[0.5,0.3]\rangle,\langle I,[0.5,0.3]\rangle\}
$$

Then $A$ is a vague positive implicative $L I$ - ideal of $L$.

Theorem 14. Every VPILI - ideal of $L$ is a VLI - ideal of $L$.

Proof. Let $A$ be a VPILI - ideal of $L$ and $x, y, z \in L$. Then we have

$$
V_{A}(y) \geq \operatorname{imin}\left\{V_{A}\left(\left(\left(y(z y)^{\prime}\right)^{\prime} x\right)^{\prime}\right), V_{A}(x)\right\}
$$

Taking $x=y, y=x, z=x$ in the above equation, we obtain

$$
\begin{aligned}
V_{A}(x) & \geq \operatorname{imin}\left\{V_{A}\left(\left(\left(x(x x)^{\prime}\right)^{\prime} y\right)^{\prime}\right), V_{A}(y)\right\} \\
& \left.\geq \operatorname{imin}\left\{V_{A}\left(\left(x I^{\prime}\right)^{\prime} y\right)^{\prime}\right), V_{A}(y)\right\} \\
& \left.\geq \operatorname{imin}\left\{V_{A}\left((x 0)^{\prime} y\right)^{\prime}\right), V_{A}(y)\right\} \\
& \geq \operatorname{imin}\left\{V_{A}\left((x y)^{\prime}\right), V_{A}(y)\right\}
\end{aligned}
$$

Hence $A$ is a VLI - ideal of $L$.

The converse of the theorm 14 may not to be true as seen in the following example.

Example 15. Let $L=\{0, a, b, c, d, I\}$ be a set with cayley table as follows: 


\begin{tabular}{|c|c|c|c|c|c|c|}
\hline$\rightarrow$ & 0 & $a$ & $b$ & $c$ & $d$ & $I$ \\
\hline 0 & $I$ & $I$ & $I$ & $I$ & $I$ & $I$ \\
\hline$a$ & $c$ & $I$ & $b$ & $c$ & $b$ & $I$ \\
\hline$b$ & $d$ & $a$ & $I$ & $b$ & $a$ & $I$ \\
\hline$c$ & $a$ & $a$ & $I$ & $I$ & $a$ & $I$ \\
\hline$d$ & $b$ & $I$ & $I$ & $b$ & $I$ & $I$ \\
\hline$I$ & 0 & $a$ & $b$ & $c$ & $d$ & $I$ \\
\hline
\end{tabular}

Define', $\vee, \wedge$ operations on $L$ as follows: $x^{\prime}=x \rightarrow 0, x \vee y=(x \rightarrow y) \rightarrow y$, $x \vee y=\left(\left(x^{\prime} \rightarrow y^{\prime}\right) \rightarrow y^{\prime}\right)^{\prime}$ for all $x, y \in L$.

Then $(L, \vee, \wedge, \rightarrow,, 0, I)$ is a lattice implication algebra[14]. Let $B$ be a vague set of $L$ defined by

$$
\begin{aligned}
B=\{\langle 0,[0.7,0.2]\rangle,\langle a,[0.5,0.3]\rangle,\langle b,[0.5,0.3]\rangle, & \langle c,[0.7,0.2]\rangle \\
& \langle d,[0.5,0.3]\rangle,\langle I,[0.5,0.3]\rangle\} .
\end{aligned}
$$

Then $B$ is a VLI - ideal of $L$, but it is not a VPILI - ideal of $L$ because

$$
V_{A}(d)<\operatorname{imin}\left\{V_{A}\left(\left(\left(d(a d)^{\prime}\right)^{\prime} 0\right)^{\prime}\right), V_{A}(0)\right\} \text {. }
$$

Now, we give an equivalent condition for a VLI - ideal to be a VPILI - ideal.

Theorem 16. Let $A$ be a VLI - ideal of $L$. Then $A$ is a VPILI - ideal of $L$ if and only if $V_{A}(x) \geq V_{A}\left(\left(x(y x)^{\prime}\right)^{\prime}\right)$, for all $x, y \in L$.

Proof. Let $A$ is a VPILI - ideal of $L$ and $x, y, z \in L$. Then we have

$$
V_{A}(y) \geq \operatorname{imin}\left\{V_{A}\left(\left(\left(y(z y)^{\prime}\right)^{\prime} x\right)^{\prime}\right), V_{A}(x)\right\} .
$$

Setting $x=0, y=x, z=y$ in the equation above, we obtain

$$
\begin{aligned}
V_{A}(x) & \geq \operatorname{imin}\left\{V_{A}\left(\left(\left(x(y x)^{\prime}\right)^{\prime} 0\right)^{\prime}\right), V_{A}(0)\right\} \\
& \geq \operatorname{imin}\left\{V_{A}\left(\left(x(y x)^{\prime}\right)^{\prime}\right), V_{A}(0)\right\}
\end{aligned}
$$




$$
\geq V_{A}\left(\left(x(y x)^{\prime}\right)^{\prime}\right)
$$

Conversely, suppose that $A$ is a VLI - ideal and satisfies the inequality

$$
V_{A}(x) \geq V_{A}\left(\left(x(y x)^{\prime}\right)^{\prime}\right) \text {. }
$$

For any $x, y, z \in L$, we have

$$
\begin{aligned}
V_{A}(y) & \geq V_{A}\left(\left(y(z y)^{\prime}\right)^{\prime}\right) \\
& \geq \operatorname{imin}\left\{V_{A}\left(\left(\left(y(z y)^{\prime}\right)^{\prime} x\right)^{\prime}\right), V_{A}(x)\right\} .
\end{aligned}
$$

Hence $A$ is a VPILI - ideal of $L$.

Theorem 17. Let $A$ is a VPILI - ideal of $L$. Then

$$
I=\left\{x \in L / V_{A}(x)=V_{A}(0)\right\}
$$

is a PILI - ideal of $L$.

Proof. Let $A$ is a VPILI - ideal of $L$ and $I=\left\{x \in L / V_{A}(x)=V_{A}(0)\right\}$. Obviously $0 \in L$. Let $x, y, z \in L$ and $\left(\left(y(z y)^{\prime}\right)^{\prime} x\right)^{\prime} \in I, x \in I$. Then we have,

$$
V_{A}\left(\left(\left(y(z y)^{\prime}\right)^{\prime} x\right)^{\prime}\right)=V_{A}(0)
$$

and

$$
V_{A}(x)=V_{A}(0)
$$

Since $A$ is a VPILI - ideal,

$$
V_{A}(y) \geq \operatorname{imin}\left\{V_{A}\left(\left(\left(y(z y)^{\prime}\right)^{\prime} x\right)^{\prime}\right), V_{A}(x)\right\}=V_{A}(0) \text {. }
$$

And $V_{A}(0) \geq V_{A}(y)$, then $V_{A}(y)=V_{A}(0)$. Thus $y \in I$. It follows that $I$ is a PILI - ideal of $L$.

Example 18. In example 13, the vague set

$$
A=\{\langle 0,[0.7,0.2]\rangle,\langle a,[0.7,0.2]\rangle,\langle b,[0.5,0.3]\rangle,\langle I,[0.5,0.3]\rangle\}
$$

is a VPILI - ideal of $L$. Define $I=\left\{x \in L / V_{A}(x)=V_{A}(0)\right\}$, then clearly $I=$ $\{0, a\}$ is a PILI - ideal of $L$. 
The following theorem shows the relation between VPILI - ideal and its level subsets:

Theorem 19. Let $A$ be a vague set of $L$. Then $A$ is a VPILI -ideal of $L$ if and only if $A_{(\alpha, \beta)}$ is a PILI - ideal of $L$ when $A_{(\alpha, \beta)} \neq \phi, \alpha, \beta \in[0,1]$.

Proof. Let $A$ be a VPILI - ideal of $L$ and $\alpha, \beta \in[0,1]$ such that $A_{(\alpha, \beta)} \neq \phi$. Clearly $0 \in A_{(\alpha, \beta)}$. Let $x, y, z \in L$ and $\left(\left(y(z y)^{\prime}\right)^{\prime} x\right)^{\prime} \in A_{(\alpha, \beta)}, x \in A_{(\alpha, \beta)}$. Then we have $V_{A}\left(\left(\left(y(z y)^{\prime}\right)^{\prime} x\right)^{\prime}\right) \geq[\alpha, \beta], V_{A}(x) \geq[\alpha, \beta]$. It follows that $V_{A}(y) \geq \operatorname{imin}\left\{V_{A}\left(\left(\left(y(z y)^{\prime}\right)^{\prime} x\right)^{\prime}\right), V_{A}(x)\right\} \geq[\alpha, \beta]$. Thus $y \in A_{(\alpha, \beta)}$. So, $A_{(\alpha, \beta)}$ is a PILI - ideal.

Conversely, suppose that $A_{(\alpha, \beta)} \neq \phi$ is a PILI - ideal of $L$, where $\alpha, \beta \in$ $[0,1]$. For any $x \in L, x \in A_{A(x)}$, it follows that $A_{A(x)}$ is a PILI - ideal of $L$ and hence $0 \in A_{A(x)}$. That is $V_{A}(0) \geq V_{A}(x)$. For any $x, y, z \in L$, let $[\alpha, \beta]=\min \left\{V_{A}\left(\left(\left(y(z y)^{\prime}\right)^{\prime} x\right)^{\prime}\right), V_{A}(x)\right\}$. It follows that $A_{(\alpha, \beta)}$ is a PILI - ideal and $\left(\left(y(z y)^{\prime}\right)^{\prime} x\right)^{\prime} \in A_{(\alpha, \beta)}$ and $x \in A_{(\alpha, \beta)}$, this implies that $y \in A_{(\alpha, \beta)}$. So

$$
V_{A}(y) \geq[\alpha, \beta]=\operatorname{imin}\left\{V_{A}\left(\left(\left(y(z y)^{\prime}\right)^{\prime} x\right)^{\prime}\right), V_{A}(x)\right\} .
$$

Hence $A$ is a VPILI - ideal of $L$.

Corollary 20. Let $A$ be a vague set of $L$. Then $A$ is a VPILI -ideal of $L$ if and only if $A_{\alpha}$ is a PILI - ideal of $L$ when $A_{\alpha} \neq \phi, \alpha \in[0,1]$.

Theorem 21. Let $A$ and $B$ be VILI - ideals of $L$ such that $A \subseteq B$. If $A$ is VPILI - ideal of $L$, then so $B$.

Proof. Let $A$ and $B$ be VILI - ideals of $L$ such that $A \subseteq B$, that is $V_{A}(x) \leq$ $V_{B}(x) \forall x \in L$. Then clearly, $A_{\alpha} \subseteq B_{\alpha}$ for every $\alpha \in[0,1]$. If $A$ is a VPILI ideal of $L$, then by corollary $20 A_{\alpha}$ is a PILI - ideal of $L$. By theorem 2.8 in [5], $B_{\alpha}$ is a PILI - ideal of $L$. So $B$ is VPILI - ideal of $L$.

Theorem 22. Let $A$ be a vague set of $L$ and satisfies the following conditions: 
1. $\forall x \in L, V_{A}(0) \geq V_{A}(x)$;

2. $\forall x, y, z \in L, V_{A}\left(\left((x z)^{\prime}(y z)^{\prime}\right)^{\prime}\right) \geq \operatorname{imin}\left\{V_{A}\left(\left(\left((x y)^{\prime} z\right)^{\prime} a\right)^{\prime}\right), V_{A}(a)\right\}$.

Then $A$ is a VILI- ideal of $L$.

Proof. For any $x, y, z \in L$, we have

$V_{A}\left(\left((x z)^{\prime}(y z)^{\prime}\right)^{\prime}\right) \geq \operatorname{imin}\left\{V_{A}\left(\left(\left((x y)^{\prime} z\right)^{\prime} a\right)^{\prime}\right), V_{A}(a)\right\}$.

Taking $z=y$ in the above equation, we get

$$
\begin{aligned}
V_{A}\left(\left((x y)^{\prime}(y y)^{\prime}\right)^{\prime}\right) & \geq \operatorname{imin}\left\{V_{A}\left(\left(\left((x y)^{\prime} y\right)^{\prime} a\right)^{\prime}\right), V_{A}(a)\right\} \\
V_{A}\left(\left((x y)^{\prime} 0\right)^{\prime}\right) & \geq \operatorname{imin}\left\{V_{A}\left(\left(\left((x y)^{\prime} y\right)^{\prime} a\right)^{\prime}\right), V_{A}(a)\right\} \\
V_{A}\left((x y)^{\prime}\right) & \geq \operatorname{imin}\left\{V_{A}\left(\left(\left((x y)^{\prime} y\right)^{\prime} a\right)^{\prime}\right), V_{A}(a)\right\} .
\end{aligned}
$$

Hence $A$ is a VILI - ideal of $L$.

Theorem 23. Let $A$ be a VLI - ideal of $L$ satisfying

$$
V_{A}\left(\left((x z)^{\prime}(y z)^{\prime}\right)^{\prime}\right) \geq V_{A}\left(\left((x y)^{\prime} z\right)^{\prime}\right)
$$

for all $x, y, z \in L$. Then $A$ is a VILI - ideal of $L$.

Proof. Let $x, y, z, a \in L$ and $A$ be a VLI - ideal of $L$ satisfying the given inequality. It follows that

$$
\begin{aligned}
V_{A}\left(\left((x z)^{\prime}(y z)^{\prime}\right)^{\prime}\right) & \geq V_{A}\left(\left((x y)^{\prime} z\right)^{\prime}\right) \\
& \geq \operatorname{imin}\left\{V_{A}\left(\left(\left((x y)^{\prime} z\right)^{\prime} a\right)^{\prime}\right), V_{A}(a)\right\}
\end{aligned}
$$

By theorem22 $A$ is a VILI - ideal of $L$. 
Theorem 24. Let $A$ be a VLI - ideal of $L$ satisfying

$$
V_{A}\left((x y)^{\prime}\right) \geq V_{A}\left(\left((x y)^{\prime} y\right)^{\prime}\right),
$$

for all $x, y, z \in L$. Then $A$ is a VILI - ideal of $L$.

Proof. Let $x, y, z \in L$ and $A$ be a VLI - ideal of $L$ satisfying the given condition. It follows that

$$
\begin{aligned}
V_{A}\left((x y)^{\prime}\right) & \geq V_{A}\left(\left((x y)^{\prime} y\right)^{\prime}\right) \\
& \geq \operatorname{imin}\left\{V_{A}\left(\left(\left((x y)^{\prime} y\right)^{\prime} z\right)\right), V_{A}(z)\right\} .
\end{aligned}
$$

Hence $A$ is a VILI - ideal of $L$.

Theorem 25. Every VILI - ideal of $L$ satisfies the inequality

$$
V_{A}\left((x y)^{\prime}\right) \geq V_{A}\left(\left((x y)^{\prime} y\right)^{\prime}\right)
$$

for all $x, y, z \in L$.

Proof. Let $A$ be a VILI - idealof $L$. Then for all $x, y, z \in L$, we have

$$
\left.V_{A}\left((x y)^{\prime}\right) \geq \operatorname{imin}\left\{V_{A}\left(\left(\left((x y)^{\prime} y\right)^{\prime} z\right)\right)^{\prime}\right), V_{A}(z)\right\} \text {. }
$$

Taking $z=0$ in the above equation, we get

$$
\begin{aligned}
V_{A}\left((x y)^{\prime}\right) & \geq \operatorname{imin}\left\{V_{A}\left(\left(\left((x y)^{\prime} y\right)^{\prime} 0\right)^{\prime}\right), V_{A}(0)\right\} \\
& \geq V_{A}\left(0^{\prime}\left((x y)^{\prime} y\right)^{\prime}\right) \\
& =V_{A}\left(\left((x y)^{\prime} y\right)^{\prime}\right) .
\end{aligned}
$$

Theorem 26. Let $A$ be a VLI - ideal of $L$. Then the following are equivalent: 
1. $A$ is a VILI - ideal of $L$.

2. $V_{A}(x) \geq V_{A}\left(\left(x(y x)^{\prime}\right)^{\prime}\right)$, for all $x, y \in L$.

3. $V_{A}(x) \geq \operatorname{imin}\left\{V_{A}\left(\left(\left(x(y x)^{\prime}\right)^{\prime} z\right)^{\prime}\right), V_{A}(z)\right\}$, for all $x, y, z \in L$.

Proof. $(1) \Rightarrow(2)$. Suppose that $A$ is a VILI - ideal of $L$, and $x, y, z \in L$.

Now clearly

$$
\begin{aligned}
\left(\left(y(y x)^{\prime}\right)^{\prime}(y x)^{\prime}\right)^{\prime}\left(x(y x)^{\prime}\right)^{\prime} & =\left(x(y x)^{\prime}\right)\left(\left(y(y x)^{\prime}\right)^{\prime}(y x)^{\prime}\right) \\
& \geq\left(y(y x)^{\prime}\right)^{\prime} x \\
& =x^{\prime}\left(y(y x)^{\prime}\right) \\
& =x^{\prime}\left((y x) y^{\prime}\right) \\
& =(y x)\left(x^{\prime} y^{\prime}\right) \\
& =(y x)(y x) \\
& =I .
\end{aligned}
$$

Since $x<I$ for all $x \in L$, it follows that

$$
\left(\left(y(y x)^{\prime}\right)^{\prime}(y x)^{\prime}\right)^{\prime}\left(x(y x)^{\prime}\right)^{\prime}=I
$$

So,

$$
\left(\left(y(y x)^{\prime}\right)^{\prime}(y x)^{\prime}\right)^{\prime} \leq\left(x(y x)^{\prime}\right)^{\prime}
$$

Since $A$ is order reversing, we have

$$
\begin{aligned}
V_{A}\left(\left(x(y x)^{\prime}\right)^{\prime}\right) & \leq V_{A}\left(\left(\left(y(y x)^{\prime}\right)^{\prime}(y x)^{\prime}\right)^{\prime}\right) \\
& \leq V_{A}\left(\left(y(y x)^{\prime}\right)^{\prime}\right) \text { (by theorem 25). }
\end{aligned}
$$


Clearly $\left(x(y x)^{\prime}\right)^{\prime} \geq(x y)^{\prime}$ and $\left(x y^{\prime}\right)=\left(x\left(y(y x)^{\prime}\right)^{\prime}\right)^{\prime}$.

Since $A$ is order reversing, we have

$$
\begin{aligned}
V_{A}\left(\left(x(y x)^{\prime}\right)^{\prime}\right) & \leq V_{A}\left((x y)^{\prime}\right) \\
& =V_{A}\left(\left(x\left(y(y x)^{\prime}\right)^{\prime}\right)^{\prime}\right)
\end{aligned}
$$

It follows from (i), (ii) and $A$ is VLI - ideal that

$$
\begin{aligned}
V_{A}(x) & \geq \operatorname{imin}\left\{V_{A}\left(\left(x\left(y(y x)^{\prime}\right)^{\prime}\right)^{\prime}\right), V_{A}\left(\left(y(y x)^{\prime}\right)^{\prime}\right)\right\} \\
& \geq V_{A}\left(\left(x(y x)^{\prime}\right)\right) .
\end{aligned}
$$

Hence (2) proved.

Obviously $(2) \Rightarrow(3)$.

$(3) \Rightarrow(1)$. Assume that $A$ satisfies the condition (3) and let $x, y, z \in L$, then we have

$$
V_{A}(x) \geq \operatorname{imin}\left\{V_{A}\left(\left(\left(x(y x)^{\prime}\right)^{\prime} z\right)^{\prime}\right), V_{A}(z)\right\}
$$

Taking $z=0$ in the above equation, we get

$$
\begin{aligned}
V_{A}(x) & \geq \operatorname{imin}\left\{V_{A}\left(\left(\left(x(y x)^{\prime}\right)^{\prime} 0\right)^{\prime}\right), V_{A}(0)\right\} \\
& =V_{A}\left(\left(\left(x(y x)^{\prime}\right)^{\prime} 0\right)^{\prime}\right) \\
& =V_{A}\left(\left(\left(\left(x(y x)^{\prime}\right)^{\prime}\right)^{\prime}\right)\right. \\
& =V_{A}\left(\left(x(y x)^{\prime}\right)^{\prime}\right)
\end{aligned}
$$

Clearly

$$
\left((x y)^{\prime}\left(x(x y)^{\prime}\right)^{\prime}\right)^{\prime}=\left((x y)^{\prime} y\right)^{\prime}
$$


It follows from (iii) and (iv) that

$$
\begin{aligned}
V_{A}\left((x y)^{\prime}\right) & \geq V_{A}\left(\left((x y)^{\prime}\left(x(x y)^{\prime}\right)^{\prime}\right)^{\prime}\right) \\
& =V_{A}\left(\left((x y)^{\prime} y\right)^{\prime}\right) .
\end{aligned}
$$

By theorem 24, $A$ is a VILI - ideal of $L$.

Remark 27. Theorem 26 shows that VILI - ideals and VPILI - ideals are equivalent in lattice implication algebra.

\section{Vague Associative LI - Ideals}

In this section, we introduce the notion of Vague associative LI - ideals and investigate some of their properties.

Definition 28. Let $A$ be a vague set of $L . A$ is said to be a vague associative $L I$ - ideal of $L$ with respect to $x$ if it satisfies the following conditions:

1. $\forall x \in L, V_{A}(0) \geq V_{A}(x)$;

2. $\forall x, y, z \in L, V_{A}(z) \geq \operatorname{imin}\left\{V_{A}\left(\left((z y)^{\prime} x\right)^{\prime}\right), V_{A}\left((y x)^{\prime}\right)\right\}$.

A vague associative LI - ideal with respect to all $x \neq I$ is called an vague associative LI - ideal.

Clearly vague associative LI - ideal with respect to $I$ is constant.

Example 29. Let $L=\{0, a, b, c, d, I\}$ be a set with cayley table as follows:

\begin{tabular}{|c|c|c|c|c|c|c|}
\hline$\rightarrow$ & 0 & $a$ & $b$ & $c$ & $d$ & $I$ \\
\hline 0 & $I$ & $I$ & $I$ & $I$ & $I$ & $I$ \\
\hline$a$ & $d$ & $I$ & $a$ & $c$ & $c$ & $I$ \\
\hline$b$ & $c$ & $I$ & $I$ & $c$ & $c$ & $I$ \\
\hline$c$ & $b$ & $a$ & $b$ & $I$ & $a$ & $I$ \\
\hline$d$ & $a$ & $I$ & $a$ & $I$ & $I$ & $I$ \\
\hline$I$ & 0 & $a$ & $b$ & $c$ & $d$ & $I$ \\
\hline
\end{tabular}


Define ', $\vee, \wedge$ operations on $L$ as follows: $x^{\prime}=x \rightarrow 0, x \vee y=(x \rightarrow y) \rightarrow y$, $x \vee y=\left(\left(x^{\prime} \rightarrow y^{\prime}\right) \rightarrow y^{\prime}\right)^{\prime}$ for all $x, y \in L$.

Then $(L, \vee, \wedge, \rightarrow,, 0, I)$ is a lattice implication algebra. Let $C$ be a vague set of $L$ defined by

$$
C=\{\langle 0,[0.7,0.2]\rangle,\langle a,[0.7,0.2]\rangle,\langle b,[0.5,0.3]\rangle,\langle c,[0.5,0.3]\rangle,\langle d,[0.7,0.2]\rangle,
$$

Clearly $C$ is a vague associative $L I$ - ideal of $L$ with respect to $c$ and $d$, but not with respect to $a$ and $b$. Because $V_{A}(a)<\operatorname{imin}\left\{V_{A}\left(\left((a c)^{\prime} a\right)^{\prime}\right), V_{A}\left((c a)^{\prime}\right)\right\}$ and $V_{A}(b)<\operatorname{imin}\left\{V_{A}\left(\left((b c)^{\prime} b\right)^{\prime}\right), V_{A}\left((c b)^{\prime}\right)\right\}$

Corollary 30. If $A$ is a vague associative $L I$ - ideal of $L$ with respect to $x$, then $V_{A}(x)=V_{A}(0)$.

Proof. Let $A$ is a vague associative LI - ideal of $L$ with respect to $x$. If $x=0,1$ then it is trivial. Assume that $x$ is neither 0 nor 1 .

Then

$$
\begin{aligned}
V_{A}(x) & \geq \operatorname{imin}\left\{V_{A}\left(\left((x 0)^{\prime} x\right)^{\prime}\right), V_{A}\left((0 x)^{\prime}\right)\right\} \\
& =V_{A}(0) .
\end{aligned}
$$

So $V_{A}(x)=V_{A}(0)$.

Theorem 31. Every vague associative $L I$ - ideal of $L$ with respect to 0 is a VLI - ideal of $L$.

Proof. Let $A$ is a vague associative LI - ideal of $L$ with respect to 0 . Then we have

$$
\begin{aligned}
V_{A}(x) & \geq \operatorname{imin}\left\{V_{A}\left(\left((x y)^{\prime} 0\right)^{\prime}\right), V_{A}\left((y 0)^{\prime}\right)\right\}, \\
& =\operatorname{imin}\left\{V_{A}\left((x y)^{\prime}\right), V_{A}(y\}\right) .
\end{aligned}
$$

Hence $A$ is a VLI - ideal of $L$.

Remark 32. The converse of the above theorm need not to be true. Clearly, the vague set $B$ of $L$ in the example 15 is a VLI - ideal of $L$. But it is not a vague associative $L I$ - ideal of $L$ with resept to 0 . 
Now, we give equivalent conditions for a VLI - ideal to be a vague associative LI - ideal.

Theorem 33. Let $A$ be a VLI - ideal of $L$. Then $A$ is a vague associative $L I$ - ideal of $L$ if and only if it satisfies

$$
V_{A}\left(\left(z(y x)^{\prime}\right)^{\prime}\right) \geq V_{A}\left(\left((z y)^{\prime} x\right)^{\prime}\right), \forall x, y, z \in L .
$$

Proof. Let the VLI - ideal $A$ of $L$ satisfies

$$
V_{A}\left(\left(z(y x)^{\prime}\right)^{\prime}\right) \geq V_{A}\left(\left((z y)^{\prime} x\right)^{\prime}\right) \text {. }
$$

Then we have

$$
\begin{aligned}
V_{A}(z) & \geq \operatorname{imin}\left\{V_{A}\left(\left(z(y x)^{\prime}\right)^{\prime}\right), V_{A}\left((y x)^{\prime}\right)\right\} \\
& =\operatorname{imin}\left\{V_{A}\left(\left((z y)^{\prime} x\right)^{\prime}\right), V_{A}\left((y x)^{\prime}\right)\right\} .
\end{aligned}
$$

So $A$ is a vague associative LI - ideal of $L$.

Conversely, suppose that $A$ be a vague associative LI - ideal of $L$. Then we have

$$
V_{A}\left(\left(z(y x)^{\prime}\right)^{\prime}\right) \geq \operatorname{imin}\left\{V_{A}\left(\left(\left(\left(z(y x)^{\prime}\right)^{\prime}(z y)^{\prime}\right)^{\prime} x\right)^{\prime}\right)^{\prime}, V_{A}\left(\left((z y)^{\prime} x\right)^{\prime}\right)\right\} .
$$

Let us consider

$$
\begin{aligned}
\left(\left(z(y x)^{\prime}\right)^{\prime}(z y)^{\prime}\right)^{\prime} x & =x^{\prime}\left(\left(z(y x)^{\prime}\right)^{\prime}(z y)^{\prime}\right) \\
& =x^{\prime}\left((z y)\left(z(y x)^{\prime}\right)\right) \\
& =(z y)\left(x^{\prime}\left((y x) z^{\prime}\right)\right) \\
& =(z y)\left((y x)\left(x^{\prime} z^{\prime}\right)\right) \\
& =(z y)((z y)(z y)) \\
& =I .
\end{aligned}
$$


It follows that

$$
\begin{aligned}
V_{A}\left(\left(z(y x)^{\prime}\right)^{\prime}\right) & \geq \operatorname{imin}\left\{V_{A}(0), V_{A}\left(\left((z y)^{\prime} x\right)^{\prime}\right)\right\} \\
& =V_{A}\left(\left((z y)^{\prime} x\right)^{\prime}\right) .
\end{aligned}
$$

Theorem 34. Let $A$ be a VLI - ideal of $L$. Then $A$ is a vague associative $L I$ - ideal of $L$ if and only if it satisfies $V_{A}(z) \geq V_{A}\left(\left((z x)^{\prime} x\right)^{\prime}\right)$.

Proof. Let $A$ be a vague associative LI - ideal of $L$.

Then we have $V_{A}(z) \geq \operatorname{imin}\left\{V_{A}\left(\left((z y)^{\prime} x\right)^{\prime}\right), V_{A}\left((y x)^{\prime}\right)\right\}$

Taking $y=x$ in the above equation, we get

$$
\begin{aligned}
V_{A}(z) & \geq \operatorname{imin}\left\{V_{A}\left(\left((z x)^{\prime} x\right)^{\prime}\right), V_{A}\left((x x)^{\prime}\right)\right\} \\
& \geq \operatorname{imin}\left\{V_{A}\left(\left((z x)^{\prime} x\right)^{\prime}\right), V_{A}(0)\right\} \\
& =V_{A}\left(\left((z x)^{\prime} x\right)^{\prime}\right) .
\end{aligned}
$$

Conversely suppose that $A$ is a VLI - ideal and satisfies the given inequality.

Clearly,

$$
\left(\left((z x)^{\prime}(y x)^{\prime}\right)^{\prime}(z y)^{\prime}\right)^{\prime}=0
$$

and

$$
\left((z y)^{\prime}(z x)^{\prime}\right)^{\prime} \leq(x y)^{\prime} .
$$

It follows that

$$
\begin{gathered}
\left(\left(\left(\left(z(y x)^{\prime}\right)^{\prime} x\right)^{\prime} x\right)^{\prime}\left((z y)^{\prime} x\right)^{\prime}\right)^{\prime}=0 . \\
V_{A}\left(\left(z(y x)^{\prime}\right)^{\prime}\right) \geq V_{A}\left(\left(\left(\left(z(y x)^{\prime}\right)^{\prime} x\right)^{\prime} x\right)^{\prime}\right)
\end{gathered}
$$




$$
\begin{aligned}
& \geq \operatorname{imin}\left\{V_{A}\left(\left(\left(\left(\left(z(y x)^{\prime}\right)^{\prime} x\right)^{\prime}\right)^{\prime}\left((z y)^{\prime} x\right)^{\prime}\right){ }^{\prime}, V_{A}\left(\left((z y)^{\prime} x\right)^{\prime}\right)\right\}\right. \\
& =\operatorname{imin}\left\{V_{A}(0), V_{A}\left(\left((z y)^{\prime} x\right)^{\prime}\right)\right\} \\
& =V_{A}\left(\left((z y)^{\prime} x\right)^{\prime}\right) .
\end{aligned}
$$

By theorm $33 A$ is a Vague associative LI - ideal of $L$.

\section{Conclusion}

Since W.L.Gai, D.J.Buehrer proposed the notion of vague sets, these ideas have been applied to various fields. In this paper, we applied these ideas to Lattice implication algebras and introduced the notions of vague positive implicative and vague associative LI - ideals. We obtained some properties of vague positive implicative and vague associative LI - ideals and established the extension theorem for vague positive implicative LI - ideals.Furthermore, we discussed the relations among VLI - ideals, VILI - ideals, VPILI - ideals and vague associative LI - ideals respectively.Also we proved VILI - ideals and VPILI - ideals are coincide in Lattice implication algebras. We hope that above work would serve as a foundation for enriching corresponding many - valued logical system.

\section{References}

[1] L.A. Zadeh, Fuzzy sets, Information and Control, 8, (1965), 338-353.

[2] Leroy B. Beasley, GI-Sang Cheon, Y.B. Jun and Seok Zun Song, Fuzzy implicative LI - ideals in lattice implication algebras, Scientiae Mathematicae Japonicae, 9, (2003), 37- 48.

[3] Liu Lianzhen, Li Kaitai, Fuzzy boolean and positive implicative filters of BL - algebras, Fuzzy Sets and Systems, 152, (2005), 333- 348, doi:10.1016/j.fss.2004.10.005.

[4] Rangit Biswas, vague groups, Int. J. Comput. Congition, 4, No.2, (2006), 20 - 23. 
[5] S. Mokhtari, A.Kordi, A.moussavi, A. Ahmadi, On LI - ideals of lattice implication algebras, J. Math. and Applications, 32, (2010), 67 - 74.

[6] T. Anitha and V. Amarendra Babu, Vague LI - ideals on lattice implication algebras, J. Emerging Trends in Computing and Information Sciences, 5, (2014), $788-793$.

[7] T. Anitha and V. Amarendra Babu, Vague implicative LI - ideals of lattice implication algebras, Mathematics and statistics, 3, No. 3, (2015), 53 57, doi: $10.13189 / \mathrm{ms} .2015 .030301$.

[8] W.L. Gau and D.J. Buehrer, Vague sets, IEEE Transactions on Systems, Man and Cybernetics, 23, No.20, (1993), 610-614.

[9] Y.B.Jun, Fuzzy positive implicative and fuzzy associative filters of lattice implication algebras, Fuzzy sets and Systems, 121, (2001), 353 - 357.

[10] Ya Qin and Yi Liu, V- filter on lattice implication algebras, Journal of Emerging Trends in Computing and Information Sciences, 3, N0.9,(2012), $1298-1301$.

[11] Y.Xu, Lattice implication algebras, J. Southwest Jiaotong University, 28, No.1, (1993), 20 - 27.

[12] Y.Xu, Y.B.Jun and E.H.Roh, LI - ideals in lattice implication algebras, Bull. Korean Math.Soc., 35, No.1, (1998), 13 - 23.

[13] Y.Xu and Y.B.Jun, Fuzzy LI - ideals in lattice implication algebras, $J$. Fuzzy Math., 7, No.4, (1999), 997 - 1003.

[14] Y.Xu, D. Ruan, K.Y.Qin, Lattice - valued Logic, An Alternative Approach to Treat Fuzziness and Incomparability, Springer, New York, (2003).

[15] Y.Xu, Young Lin Liu, San Yang Liu, Ke Yun Qin, ILI - ideals and prime LI - ideals in lattice implication algebras, Information Sciences, 155, (2003), 157 - 175, doi: 10.1016/s0020-0255(03)00159-2. 
